\title{
Measurement of regional poverty in Tunisia: A descriptive approach
}

\author{
Lasaad Jebali \\ International and Regional Economic Integration Laboratory, University Tunis EL MANAR, Faculté des Sciences Economiques et de \\ Gestion de Tunis, Tunis, Tunisia
}

Email address:

lassaad.jebali@gmail.com

\section{To cite this article:}

Lasaad Jebali. Measurement of Regional Poverty in Tunisia: A Descriptive Approach. Journal of World Economic Research. Special Issue: Issues and Challenges of the Financial and Economic Crisis Throughout the World. Vol. 3, No. 6-1, 2014, pp. 1-8.

doi: 10.11648/j.jwer.s.2014030601.11

\begin{abstract}
Our objective of this paper is double: searching in economic theory about the divergence between concept of poverty and the regional dimension social inequality. This divergence may biases estimates of poverty rates. This largely depends on measurement tool and the use indicator target. We propose later to response for: if the problem is disruptive of an economic policy which aims to targeting the poor in regions parts. In addition, we dissect, theoretically the steps of measuring poverty and the poverty trend in recent years in the developing world and we are developing a regional approach to the training levels of the poor.
\end{abstract}

Keywords: Region, Poverty, Index, Growth Rate, Education, Formal Sector

\section{Introduction}

Our aim of this paper is multiple: First, recognize the difficulty of beginning, define and conceptualize poverty. We try to give the origin of the one dollar as the poverty internationally measurement. Obviously, the design of divergence resulted in different theoretical approaches. We develop measurement approaches with multifaceted phenomenon. Then, we focus attention on a new aspect of poverty emerged in recent years; the widespread poverty provides a ratio more than $50 \%$ in some countries. Subsequently, we will try to make statistical purposes by introducing Regional Economic analysis applied to the case of Tunisian governorates. Finally, we conclude.

\section{Basis of Choice of Dollar as International Poverty Line}

The international objective of development from 1990 to 2015 aims the reduction of the half $\mathrm{n}$ of extreme poverty in the world, especially in poor countries (LDC).

It should be remembered that extreme poverty is a situation where the level of consumption does not exceed a dollar / day. The origin of this standard was established by the World Bank, after some research on the way in which the national poverty lines are constructed in less developed countries (LDC) and other developing countries. This research has the following results:

- Countries set their national thresholds, and consistent with the standard definition of the World Bank poverty, depending on the level of development of the country. There is a tendency to link the national poverty lines following the evolution of GDP and per capita consumption: More GNP and the level of consumption, national poverty line will be higher.

- In a study of twelve countries, the authors Ravallion, Datt and van de Wall (1991), the poverty line dollar / day is an indicator of purchasing power. Indeed, this definition means that poor belonging to one of these countries do not get more than a US dollar valued at 1985 prices.

- Finally, the third conclusion is that, if we admit that the setting of a national poverty in some countries following the same trend as the GNP and the level of per capita consumption, we note that in some countries, if the level of consumption per capita is less than $\$ 1,000$ / year (PPA, 1985) while the national poverty line is close to a dollar / day. Nevertheless, another group of countries whose consumption exceeds $\$ 1,000$ 
/ year (PPA 1985), while the national poverty line is then close to two dollars / day. This threshold is increasingly used by the World Bank in its analysis of poverty. It is considered to correspond to national thresholds for lower middle income countries ${ }^{1}$.

Some authors suggest some weaknesses of using the poverty line of one dollar and two dollars/ day:

The first critical given these definitions show that if global efforts are focused on the reduction of extreme poverty (less than a dollar / day), then, is that the poverty line of two dollars / day is a situation of extreme poverty? Boltvinik (1996) shows in an empirical study of some Latin American countries that the threshold of two dollars / day can be interpreted as a measure of malnutrition and physical sustenance. In this context, and according to this author, the threshold of a dollar / day does not make sense since individuals with less than a dollar a day (poverty required) would be "technically dead".

The second critic given to these definitions shows that the use of exchange rates (PPP), which compare the purchasing power of a dollar in different countries may a bias estimates, selection and specification of classes poor. Lipton (1996), Deaton (2000) and Milonvic (2000) reported that the revised estimates of poverty (PPP) in 1993 instead of 1985 significantly altered the ratio of poverty. This is due to the economic changes that characterize the world economy during the $90 \mathrm{~s}$.

The last critic shows that the use of a threshold dollar and two dollars / day does not eliminate the use of national poverty. Each country may have its own definition and its own poverty. International thresholds are, in fact, used for international comparisons. Such divergence estimates of national and international poverty can be attributed to the different choice of national and international poverty lines. Each country specifies the poverty line based on purely individual objectives of economic policy. In our opinion divergence and the nature of the debate on the use of these thresholds is originally from a conceptual problem related to the issue of poverty. This prompted us to review the different types discussed in the literature.

\section{Typologies of Poverty}

Poverty is the subject of various types, we will present in the following successively three different types, that of Rosenthal, that Zuckerman and finally that of the World Bank.

\subsection{Typology Assessment of Poverty by Gerth Rosenthal $(1989)^{2}$}

This poverty assessment typology identifies five types of poverty:

\footnotetext{
${ }^{1}$ The World Bank finds that the poverty two dollars / day may also be used for the least developed countries (World Bank, 2000).

${ }^{2}$ Executive Secretary of the Economic Commission for Latin America and the Caribbean (ECLA).
}

Type I: includes the part of the population with little material wealth, low levels of education and who cannot easily access the pressure groups (unions and political parties...) to make their demands heard ${ }^{3}$.

Type II: poverty includes persons who, because of their age, are not part of the labor force of the economy and who are deprived of minimum resources to survive. In addition, these persons do not benefit from social protection. This category also includes poor women who simultaneously work and are responsible for the family's allocations.

Type III: consists of part of the population who are victims of various forms of discrimination (linguistic, social, racial, etc.): it is a non-monetary approach to poverty. This type of poverty is present in countries with racial and religious diversity. This kind of poverty generally leads to sociopolitical conflicts, instability and sometimes even coups.

Type IV: For persons who have the qualifications and skills needed to obtain a stable job, but they are affected by adverse macroeconomic conditions. This type of poverty can be easily eradicated by adequate economic growth rate. Economic growth absorbs unemployment by hiring the skilled labor. Therefore in countries with strong economic growth, the fourth type of poverty is almost absent.

Type $V$ : Includes persons who are victims of technological innovations, because they are not making the required qualification. These are the people whose training and qualifications would find depreciated by continuous innovation. Therefore, they find it difficult to fit on the labor market. They are counted as poor because their income will be affected by the lack of generating scientific knowledge resources.

\subsection{Typology Assessment of Poverty by Zuckerman}

There are three categories of poverty:

The first category includes the new poor. These are the persons who lost their jobs in the private or public sector as a result of austerity measures.

The second category consists of people living just above the poverty line. They are qualified as vulnerable. Indeed, these individuals are often sensitive to changes in commodity prices. They are vulnerable because they are sensitive to the reduction envisaged by the government as compensation funds, welfare and especially the structural adjustment policies social spending.

The third category includes individuals who live in a structural or extreme poverty. They are victims of malnutrition, illiteracy, poor health, high infant mortality rates and a relatively short life expectancy.

\subsection{Typology of Poverty Assessment According to the World Bank}

It distinguishes three types of poverty:

The first type consists chronically poor: poverty has deep

\footnotetext{
${ }^{3}$ The concept of poverty in recent years gives priority to poor people to express themselves and describe how they themselves see their situation: Giving voice to the poor (the voice of the poor) (Trine Monsted, UCB, 2000).
} 
roots and is explained as the result of multiple deprivations: malnutrition, poor health, lack of access to productive assets etc. This type of poverty is similar to extreme poverty defined by Zuckerman.
The second type includes the new poor and finally the third is made up of vulnerable groups. Table (1) below, summarizes these different classifications.

Table 1. Types of poverty

\begin{tabular}{|c|c|c|c|}
\hline & chronic poverty & vulnerable groups & new poor \\
\hline $\begin{array}{l}\text { Rosenthal } \\
(1989)\end{array}$ & $\begin{array}{l}\text { Groups with little material wealth, } \\
\text { low education (I) and discrimination } \\
\text { (III). }\end{array}$ & $\begin{array}{l}\text { Woman heads of household with } \\
\text { children and the elderly without social } \\
\text { protection (II). }\end{array}$ & $\begin{array}{l}\text { Skilled workers, victims of bad } \\
\text { macroeconomic conditions (IV) and } \\
\text { technological innovations (V). }\end{array}$ \\
\hline $\begin{array}{l}\text { Zuckerman } \\
\text { (1989) }\end{array}$ & $\begin{array}{l}\text { Groups victims of illiteracy, } \\
\text { malnutrition, high mortality rates and } \\
\text { short life expectancy. }\end{array}$ & $\begin{array}{l}\text { Groups affected by changes in } \\
\text { commodity prices, reduced social } \\
\text { spending, adjustment measures. }\end{array}$ & $\begin{array}{l}\text { Groups of individuals who have lost their jobs } \\
\text { following the austerity measures. }\end{array}$ \\
\hline $\begin{array}{l}\text { Banque Mondiale } \\
\text { (1990) }\end{array}$ & $\begin{array}{l}\text { Groups of individuals that their } \\
\text { situation has deep roots and is the } \\
\text { result of deep deprivation. }\end{array}$ & $\begin{array}{l}\text { Groups above the poverty line but they } \\
\text { are affected by the adjustment policies. }\end{array}$ & $\begin{array}{l}\text { Groups above the poverty line but become } \\
\text { poor as a result of austerity measures. }\end{array}$ \\
\hline
\end{tabular}

Source: Author's compilation

These three types establish three to five poverty subsets (subgroups), although the boundaries between sub-groups are not well defined. Nevertheless, the three types insist on at least two types of poverty:

- The Structural and permanent poverty affect negatively sustainable growth and economic development.

- The cyclical poverty linked to economic austerity measures and structural adjustments that affect vulnerable and economically fragile social category. This poverty can disappear in the short term if there will be improve of economic conditions. These typologies were able to highlights on the real causes of this scourge. This of course leads us to the address in the following paragraph:

\section{Causes of Poverty}

We cites as direct causes of poverty: the low rate of economic growth, stagnant productivity, unemployment and underemployment, low level instruction, rapid population growth and political violence.

\subsection{A low Economic Growth Rate}

When economic growth rate of a country is below the population per capita income, we are in a bad situation.

This decrease may be associated with an increase in poverty and more vulnerable in this situation people find refuge in the informal sector to offset the decline in income.

Moreover, when growth rate is low, number of jobs created is insufficient to create jobs. A weakness of opportunities in the formal sector, many persons found their own jobs in the informal economy.

The experience of some countries (especially the South East Asia) in recent years has shown positive impact of growth on poverty reduction. However, it is not clear that growth will lead to a more equal distribution of the newly generated revenue. Economic growth seems to be a necessary prerequisite for overcoming poverty status. However, if it is sufficient, it seems increasingly questionable ${ }^{4}$.

\subsection{Constant Productivity}

Income levels and life are affected by the trend in productivity. Indeed, the experience of some Asian countries ${ }^{5}$ has shown that the growth of per capita income results from higher and higher productivity level. Conversely, low productivity reduces income and increases poverty.

When public companies are closing or contract, the unemployed workers who are skilled and vulnerable (according to the assessment of poverty Zuckerman and the World Bank $^{6}$ typology) took refuge in the informal sector with low level of productivity.

\subsection{Unemployment and Underemployment}

Unemployment and underemployment are the results of low economic growth rates, which in turn led more persons to live below the poverty line. These seek to obtain a marginal employment as an alternative or a survival strategy. In another way, high growth rates can decrease poverty, either directly through its positive effect on job creation and opportunities, or indirectly by increasing public resources for programs targeting poor (Burki,1990).

\subsection{A Week Level of Education}

A low level of education translates into a lack of skills, which in turn can limit job opportunities for individuals. The latter may find employment in the informal sector which some of its features are the low level of organization and practice on a small scale that does not require qualifications. Alternatively, facilitate the access of the population to education can contribute to the improvement of living standards and promote growth in general.

\footnotetext{
${ }^{4}$ Burki (1990) and Rosenthal (1989).

${ }^{5}$ Franco A. Vecelli (the reduction of poverty in Peru: The search for sustainable social development -April 1997).

${ }^{6}$ See Section 1.
} 


\subsection{High Fertility Rates and Rapid Population Growth}

When population growth is rapid, it can contribute to a slowdown in the growth rate of per capita income, the expansion of the labor force and increase the number of people without qualifications. In addition, high birth rates result in an increased incidence of mortality and maternal morbidity. Moreover, poor maternal health is a handicap to take charge of their children's care, and negatively influencing the physical and mental development of these children and reducing their future prospects to overcome poverty.

\subsection{The Political Violence}

Political violence contributes many categories of poverty:

- It would force governments to allocate public resources to replace the destroyed infrastructure (violence) rather than improving social programs.

- It increases the costs for private voice by excessive spending on security companies.

- It encourages a speculative economic behavior across borders.

- It pushes people to give priority to security rather than social issues.

All these consequences of political violence hinder the ability of a government to develop programs to reduce poverty.

\section{Measurements of Poverty}

Studying poverty stems start from consumer theory and the concept of well-being. His study often requires passing through stages qualified by theorists as necessary to determine a poverty profile. Indeed, this concept "multiplefacet" requires, as a first step, to be well defined. Thereafter, it is to select the best indicator of standards living (income, consumption, etc.) to be able to determine a boundaries or poverty line. Finally, choose a synthetic index of poverty. This section will review the poverty concept in its approaches: absolute and relative. We quickly examine the different poverty lines .We finally show its various commonly used indices.

\subsection{Absolute Poverty and Relative Poverty}

\subsubsection{Absolute Poverty}

Although poverty is long measured in monetary terms, the reality is that it has other issues (poverty is multidimensional). In fact, a person is considered poor when not only fails to meet basic consumption needs to sustain life, but also when he hasn't resources security, food, literacy accompanied by a feeling of helplessness. We're talking about absolute poverty when a person is unable to meet its basic needs. In practice, we adopt a poverty line and all the people who are below this line are considered poor.

\subsubsection{Relative Poverty}

In contrast to the first approach, the relative poverty takes into account the standard of living of the entire population of the country, it takes into account inequality. It was decided that a fraction of the population is poor, for example, $20 \%$ of households with the lowest incomes.

Once an approach has been adopted, the second step is to choose an indicator of standard of living (consumption, income ...) in order to stop a poverty line.

\subsection{The Poverty Lines}

There are basically two types of lines. The first is measured in relative terms and the second in absolute terms.

A poverty line is called on when set in relation to the overall distribution of income or consumption. For example, it can be set at $50 \%$ of average income or average consumption. In the case of Tunisia and a regional approach, the poverty line adopted in this paper is the average regional income during the period 2000-2011.

As regards the absolute poverty line, it is set by estimating a cost of a basket of goods nutritional considered a minimum to ensure strict survival of an individual or a household which is added a some provision to cover non-food needs.

Once the poverty line determined, the last step is to choose synthetic indices. The most known and used of these indices are those developed in 1984 by the authors Foster, Greer, Thorbecke (FGT) index and Sen (1979).

\subsection{Poverty Indices}

\subsubsection{The Ratio of Poverty (Head Count)}

This is the part of the population whose income or consumption falls below the poverty line. The share of the population that cannot buy the basket of goods defined as the minimum subsistence. This ratio is defined by:

$$
H=\frac{q}{n}
$$

With:

q: the number of poor with an income below the threshold (line) poverty denoted $\mathrm{Z}$.

$\mathrm{n}$ : the size of the population.

When $=0,4$ it means that $40 \%$ of the population is poor.

The authors Foster, Greer, Thorbecke (1984) developed a poverty index of the general formula uses a parameter $(\propto)^{7}$ and is written in the form bellow:

$$
P_{\alpha}=\frac{1}{n} \sum_{i=1}^{q}\left[\frac{Z-Y_{i}}{Z}\right]^{\alpha} \text { with } \quad Y_{i} \prec Z
$$

q: the number of poor with income below the poverty line. $\mathrm{n}$ : the size of the population.

$Z$ : threshold or poverty line.

$Y_{i}$ : Income of the individual (i), the sum is only on the income of poor people ( 1 to q). In practice, we use household income rather than on individuals one. if $\alpha=0, P_{0}=\mathrm{H}$.

\footnotetext{
${ }^{7}$ Expresses the degree of aversion to poverty and can take multiple values.
} 


\subsubsection{The Depth of Poverty (Poverty Gap)}

This is the average difference in income or consumption relative to the poverty line, it is defined by the following formula:

$$
P_{1}=\frac{1}{n} \sum_{i=1}^{q}\left[\frac{Z-Y_{i}}{Z}\right] \quad(\alpha=1)
$$

The poverty gap can be otherwise obtained by multiplying the ratio of the income gap (I) by the ratio $\mathrm{H}$ (or $P_{0}$ ):

$$
P_{1}=I * H \text { with } I=\left(\frac{Z-Y_{q}}{Z}\right)
$$

$Y_{q}:$ the average income of the poor, $Y_{q}=\frac{1}{q} \sum_{i=1}^{q} Y_{i}$

This index (I) has particular interest: it is not only interesting to know the proportion of the poor, but also their income compared to the situation that would allow them to get out of this state. Is interpreted as the share of average income or average consumption affect the poor need to reduce the level of poverty.

\subsubsection{The Severity of Poverty}

This measure takes into account inequality among the poor It assigns greater weight to households located further away from the poverty line. The severity of poverty is calculated as follows:

$$
P_{2}=\frac{1}{n} \sum_{i=1}^{q}\left[\frac{Z-Y_{i}}{Z}\right]^{2} \quad \text { with }(\alpha=2)
$$

\subsubsection{Sen Index (1976)}

It includes in its calculation, the ratio of poverty $P_{0}($ or $\mathrm{H})$, the income gap and the Gini coefficient of inequality in the poor noted $\left(G_{p}\right)$.

$$
S=\left[I+(1-I) G_{p}\right]
$$

$\mathrm{S}$ is an increasing function of $(\mathrm{H})$ of $(\mathrm{I})$ and $\left(G_{p}\right)$ with $\left.\left.\frac{\partial S}{\partial H}\right\rangle \frac{\partial S}{\partial I}\right\rangle \frac{\partial S}{\partial G_{p}}>0$

This last inequality shows that $\mathrm{S}$ is more sensitive to the improvement in the ratio of poverty $(\mathrm{H})$ rather than improving income distribution in the poor. This index is of particular importance. Indeed, it indicates that the most efficient strategy to reduce poverty is to help those less needy first and most needy last.

Compared to the indices presented above, synthesize indicators that joint analysis makes some logical index constructed by Amartya Sen's interest. This joint analysis can even be regarded as indispensable to the extent that each indicator in isolation could be misinterpreted.

The contribution of this index is to simultaneously consider the proportion of the poor, the intensity of poverty and unequal income distribution among the poor.

The poverty rate of a country is measured by the proportion of individuals living in households with equivalent income (ie a standard of living) below a threshold equal to $60 \%$ of the median national equivalent income.

The poverty rate reflects the proportion of poor people in the population; it does not take into account the intensity of poverty. Indeed, the same rate may correspond to significantly different situations that poor households are near or far from the threshold income. This difference can be measured in absolute terms or as a percentage of the threshold. Thus, the intensity provides different information than the rate of poverty: it measures an average distance between the poor and the line that defines poverty. When measured in absolute terms, the poverty gap indicates the amount of transfer that would take an average paid to each poor household that all reach the poverty line, a factor approximately equal to the number of group consumption in each household.

\subsubsection{Measurement of the Concentration of Income Gini Indicators}

We try to answer the following question: national revenues are concentrated in certain areas or not?

The Gini coefficient takes the following form: $G=1-$ $\sum_{r=1}^{R} \frac{1}{R}\left(\lambda_{r(n)}+\lambda_{r(n+1)}\right)$

$\lambda_{r}$ Represents the share of region $\mathrm{r}$ in total electricity national wealth.

Each term of the sum is the twice of the area of trapezoid bounded by the nth and $(n+1)$ th region, located below the Lorenz curve. The Gini index, which is called absolute, gives a measure of the concentration with respect to a reference that is a uniform distribution in which each region is a same fraction $1 / \mathrm{R}$ of the total job.

The index values are between 0 and 1 . A high concentration of income in specific regions means that the value of $G$ is close to unity, otherwise ( $G$ close to 0 ), revenues are equitably distributed between regions or governorates.

\section{Regional Poverty in Tunisia: Statistical Evaluation}

To apply this modeling approach, we will study the evolution of regional poverty in Tunisia.

\subsection{Overall Statistical Regional Approach}

We assume that individuals are Tunisian governorates. National revenue is approximated by the electric GDP measured by the high speed power consumption.

We assume that the poverty line is the regional electric income average (GDP.

According to the calculations of indicators: H, P, I, G and $\mathrm{S}$ we can extract the following conclusions on the case of regional poverty in Tunisia. Table 2 below illustrates the variation of non-parametric statistical measures of poverty. 
According to the criterion Head count at least 60\% (except in 2009 where poverty is less than $60 \%$ ) of Tunisian regions are below the average of electric regional revenue during the study period. Regions: Tataouine, Siliana Kbelli Sidi Bouzid, Beja, Mahdia, Jendouba, Kairouan, Manouba, Kasserine, Ariana, Gafssa, Kef and Zagouane are below the poverty line during the period 2000-2010. In 2009 Zagouane left the club of poor areas to regain it in the following year. In 2002, the regions, Gabes and Medninne are below the poverty line and they left without returns the club of poor during the following years.

Table 2. Indicators of poverty in Tunisia

\begin{tabular}{llllllll}
\hline & $\mathbf{Q}$ & $\mathbf{H}$ & $\mathbf{P}_{\mathbf{1}}$ & $\mathbf{I}$ & $\mathbf{G}$ & $\mathbf{P 2}$ & $\mathbf{S}$ \\
\hline 2000 & 15 & 0,625 & 0,362 & 0,421 & 0,52083 & 0,0054 & 0,45160036 \\
2001 & 15 & 0,625 & 0,356 & 0,43 & 0,53904 & 0,0052 & 0,460783 \\
2002 & 17 & 0,708 & 0,362 & 0,489 & 0,53898 & 0,0055 & 0,5412085 \\
2003 & 15 & 0,625 & 0,366 & 0,414 & 0,53888 & 0,0057 & 0,4561148 \\
2004 & 15 & 0,625 & 0,369 & 0,409 & 0,53894 & 0,0058 & 0,45469596 \\
2005 & 15 & 0,625 & 0,373 & 0,403 & 0,53859 & 0,0058 & 0,45283639 \\
2006 & 15 & 0,625 & 0,373 & 0,362 & 0,53857 & 0,0058 & 0,41136927 \\
2007 & 15 & 0,625 & 0,374 & 0,403 & 0,53854 & 0,006 & 0,45281774 \\
2008 & 15 & 0,625 & 0,36 & 0,423 & 0,53863 & 0,0054 & 0,45861844 \\
2009 & 14 & 0,583 & 0,368 & 0,369 & 0,53857 & 0,0056 & 0,41325236 \\
2010 & 15 & 0,625 & 0,356 & 0,43 & 0,53864 & 0,0053 & 0,4606405 \\
\hline
\end{tabular}

Source: Author's compilation

Under the terms of the poverty gap (P1), interpreted as the share of average income must be allocated to poor to reduce the level of poverty. For the case of Tunisian regions, we must find the necessary mechanisms to provide at least $36 \%$ of average income in favor of electric lagging regions and to reduce and eliminate relative poverty.

The poverty gap (P1) is interpreted as the share of average income which must be allocated to poor to reduce the level of poverty. For the case of Tunisian regions, we must find the necessary mechanisms to provide at least $36 \%$ of average income in favor of electric lagging regions and to reduce and eliminate relative poverty.

Under the terms of the indicator I: it is not only interesting to know the proportion of the poor, but also their income compared to the situation that would allow them to get out of this state. In Tunisia, the poor need to increase at least $40 \%$ of regional income to catch governorates with regional incomes above the national average.

Poverty is severe in Tunisia, according to $\mathrm{P}_{2}$, the variance of the backward regions compared to the average income is stable over the period 2000-2010.

Using approximate electric GDP measure, the GDP per governorate, we can calculate the Gini index of the Tunisian national GDP among governorates during the period 20002010. Table 2 gives the values of $\mathrm{G}$ :

From Table 2 shows that national GDP is relatively concentrated in certain regions or governorates during the period 2000-2010. Indeed, the values of $G$ are greater than 0.5 .
Similarly, to measure the inequality distribution or dispersion of per capita income in a regional area, several indicators that Gini this is best known although it is unable to give the causes of regional disparities in the distribution of national GDP.

Gini coefficients does not give a definite conclusion about regional distribution of GDP: $12.49 \%$ of the national GDP in 2000 was carried out in Tunis, $10.29 \%$ and $11.24 \%$ in Nabeul Sousse, while the share of Tataouine is $0.48 \%$ of the wealth national in 2000 (see Jebali 2013).

According Sen indicator, it is remarkable that the $60 \%$ threshold of sustainable poverty given: concentration measurements of income and poverty gap is observed during the period 2000-2010. In fact, and according to the following figure 1 , the indicator Sen could not be above $60 \%$. It is neighbor to $50 \%$.

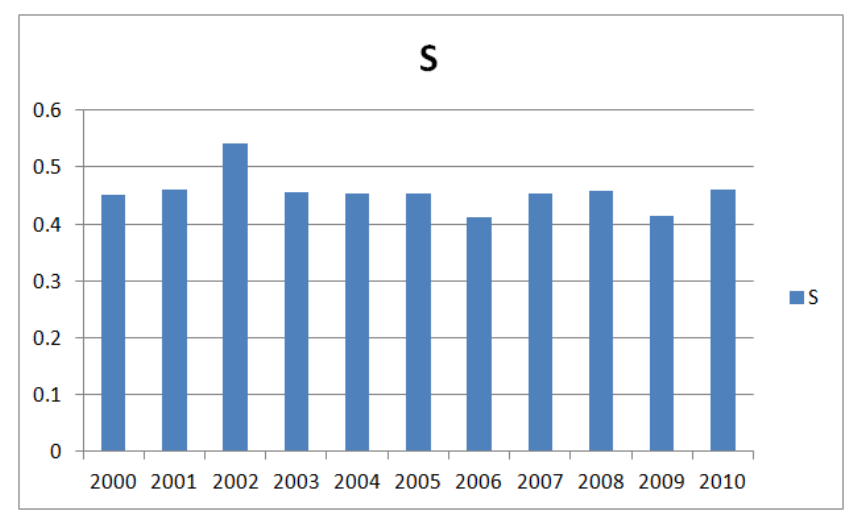

Source: Author's illustration

Figure 1. Evolution of the indicator for Sen 2000-2010

\subsection{Identification of Poverty in Tunisia}

According to data from the National Institute of Statistics (INS) in 2005, we can synthesize in Table 3 , the expenditure situation of Tunisian families and individuals living in different categories of Tunisian households.

Table 3. Household and individuals Expenditure in 2005 DT

\begin{tabular}{lll}
\hline $\begin{array}{l}\text { individuals per } \\
\text { family }\end{array}$ & $\begin{array}{l}\text { expenditure level per } \\
\text { individuals }\end{array}$ & $\begin{array}{l}\text { level of household } \\
\text { expenditure }\end{array}$ \\
\hline de 1 à 2 & 2876 & 4845 \\
de 3 à 4 & 2381 & 8560 \\
de 5 à 6 & 1669 & 9003 \\
de 7 à 8 & 1209 & 8869 \\
de 8 à 9 & 1025 & 10259 \\
\hline
\end{tabular}

Source: Author's compilation

We note that in Tunisia, extreme poverty is excluded, even if the individual is a member of a grand family, the daily expenditure is greater than one US dollar a day ${ }^{8}$. According to the criterion of poverty line of two dollars, we note that the smaller families (less than 6) are not poor. But grand families ${ }^{9}$ are poor and individuals spend no more than two

\footnotetext{
${ }^{8} 1 \$=1.5 \mathrm{TND}$

${ }^{9}$ Families with more than 6 numbers are generally residents of rural areas, and
} 
dollars per day.

The average expenditure of individuals in Tunisia in 2005 is distributed according to Table 4 as following:

Table 4. Percentages of Tunisian spending 2005 DT

\begin{tabular}{lll}
\hline Allocations & $\begin{array}{l}\text { average individual } \\
\text { expenditure in DT 2005 }\end{array}$ & Pourcentage in \% \\
\hline Nutrition & 634 & 34.83516484 \\
Housing & 414 & 22.74725275 \\
Clothing & 160 & 8.791208791 \\
health and cleanliness & 188 & 10.32967033 \\
Transportation & 195 & 10.71428571 \\
Communication & 67 & 3.681318681 \\
Education & 50 & 2.747252747 \\
Culture and leisure & 103 & 5.659340659 \\
other dépenses & 9 & 0.494505495 \\
Total & 1820 & 100 \\
\hline
\end{tabular}

Source: Author's illustration

We note that the Tunisian spend just to survive. Indeed, about $57 \%$ of expenditure for consumption and housing. Leisure is not a remarkable demand for Tunisian. Indeed, Tunisian spends only $5.66 \%$ as culture and leisure. According to the ranking of poverty Rosenthal (1989) and Table 3, the majority of Tunisians are from vulnerable groups to changing of economic structures.

\section{Tools to Reduce Poverty}

The solution is a social and economic program based on the increase of productivity. For that several measures are needed to reduce the number of poor and based on:

- Increase access of the poor to productive assets (land, credits).

- Invest in supporting the productive poor and increase the return on assets held by the poor through higher levels of investment in economic and social infrastructure.

- Develop programs to generate income, and higher wages.

- Ensure and compel education, care to increase their stock of human capital and increase their productivity and income in the long term.

This socio-economic program requires the mobilization of financial resources.

Generally reducing poverty can be in two channels, one direct and the other indirect. The direct approach assumes that the poor are deprived of access to land, employment, capital, and credit, the poverty alleviation programs must take the form of direct government intervention through special programs to increase the incomes of disadvantaged groups (special employment programs and financial assistance designated to secure additional income to the poor through self employment). The indirect approach focuses on identifying policies to implement to promote economic growth, reducing poverty in the long term.

cities with high densely of neighborhoods.

${ }^{10}$ Represent expenditures required by the Islamic culture of citizens

\section{Conclusion}

We note that poverty is a characteristic of developing countries or poor countries. Tunisia poverty is concentrated in the inner region and governorates to low population density (Jebali 2013). Attempts to rescue these regions during the period 2000-2010 do not contribute to poverty reduction or change the structure of society.

Tunisian person is poor when he is from rural origin or noncoastal governorate. His expenditures are focused on acquisitions to survive (consumption plus housing more health).

According to the different measures of regional poverty indicators, the serious rescue is possible. Indeed, the Tunisian poverty is extreme, according to rankings by the World Bank it is possible to go from being a poor country to a developing country through institutional means of good governance.

Poverty in Tunisia is a fundamental crisis related to the distribution of national GDP between persons and regions. This weakness is related to inefficient political choices such as promoting some activities near to sea in the tourism sector and ignoring agricultural sector in other regions.

To change the status of a poor country to a country where there is no inequality, it exist a fundamental path to follow:

- Stimulate economic growth, which has a positive effect on the generation of productive employment and increased public resources that can be allocated to social programs.

- Build programs that improve the prospects of the poor to generate income.

- Build targeting programs such as direct government intervention to improve the living conditions of the poor, their life expectancy through providing them with the necessary resources to nutrition, health care etc.

\section{References}

[1] Banque Mondiale, " Pauvreté », Rapport sur le Développement dans le Monde, (1990).

[2] Ben Zakour A., «Valeur ajoutée, emploi et revenu dans le secteur informel Tunisien (Etude Empirique sur Trois activités) », Thèse De Doctorat d'Etat -F.S.E.G Tunis, (Septembre 1998).

[3] Conférence de Nations Unies sur le commerce et le développement "Echapper au piège de la pauvreté ", (Rapport 2002).

[4] Hersheli G. \& Yoshiaki A. «A theory of the informal sector« Document de travail de NBER Nº823 (Décembre, 2002).

[5] Jebali L., « Dépendance régionale et inégalité des revenus en Tunisie ", Revue de développement régional, $\mathrm{N}^{\circ} 3$ septembre 2013 page 22, (2013).

[6] Jebali L., « Space Dynamics and Improvement of the Total Factor Productivity», International Journal of EuroMediterranean Studies, vol 7, $\mathrm{N}^{\circ} 1$ page 79-98 (2014).

[7] Lennart E., «informality, firm size and economic growth: testing for the De Soto hypothesis«, Département de l'économie, univerisité Brown, (Octobre 2002). 
[8] Mozaffar Q. « note on the measurement of poverty and vulnerability in the South Africa Context«, Journal of International Development $\mathrm{N}^{\circ} 14$ (p 757-772), (2002).

[9] Myles J. \& Arnett Picot P., » Poverty Indices and Polysis Analysis", Review of Income and Wealth, Série 47-N², (Juin2000).

[10] Philippe A., «L'économie informelle au Maghreb : une perspective comparatiste », Editions GRATICE, (2002).

[11] Salama P. \& Destremau B., « De nouvelles causes au Maintien de la pauvreté ", Revue de Tiers Monde $\mathrm{N}^{\circ} 167$, (Septembre 2001).
[12] William F. «Informality revisited«, World Bank policy Research, document de travail N²965, (Janvier 2003.)

[13] William F., « Are Labor Markets in Developing Countries Dualistic? ", Document de travail de la Banque Mondiale N¹941, (1998).

[14] Zidouni H., « L'économie non observée : approche comptable, cas des comptes nationaux Algériens », Editions GRATICE, (2002). 